\title{
MEASURED VELOCITIES AND ICE FLOW IN WILKES LAND, ANTARCTICA
}

\author{
by
}

\author{
N.W. Young, I.D. Goodwin, N.W.J. Hazelton, and R.J. Thwaites
}

(Australian Antarctic Division, Channel Highway, Kingston, Tasmania 7050, Australia)

\section{ABSTRACT}

Ice velocity, surface elevation, and ice thickness were measured along oversnow traverse routes in the sector of Wilkes Land, East Antarctica, bounded by long. $93^{\circ}$ and $131^{\circ} \mathrm{E}$, and the coast and lat. $75^{\circ} \mathrm{S}$. The velocity measurements show that the ice flow varies smoothly in both direction and magnitude over a distance scale of at least 20 times the ice thickness, and that it is in the direction of the surface slope averaged over a similar distance scale. A comparison of the mean horizontal shear strain-rate with the driving stress supports a power-law relation for the bulk rheology of the ice sheet with an exponent between 3 and 3.2

\section{INTRODUCTION}

Measurements of ice velocity, surface elevation, and ice thickness in Wilkes Land are used to describe the flow regime of a large sector of the East Antarctic ice sheet and to investigate its bulk flow properties. The study region extends to about $900 \mathrm{~km}$ from the coast and is approximately $1600 \mathrm{~km}$ across; an area of about $1.4 \times 10^{6} \mathrm{~km}^{2}$. An overall aim of the survey programme was to collect a data set representative of the flow of the thicker ice sheet in the interior of Antarctica in order to formulate the processes which control its motion. A supplementary aim was to determine the mass budget of a significant part of the ice sheet and to detect current changes in its mass distribution. Measurements were made on oversnow traverses along three main transects of Wilkes Land (see Fig. 1).

Data from one transect, which roughly follows a flow line south of Casey, shows the change from the very slow flow of the interior to the faster flow nearer the coast. Data from a second transect, which approximates the $2000 \mathrm{~m}$ elevation contour between long. $94^{\circ}$ and $131^{\circ} \mathrm{E}$, are used to test the uniformity of the flow around the sector. The

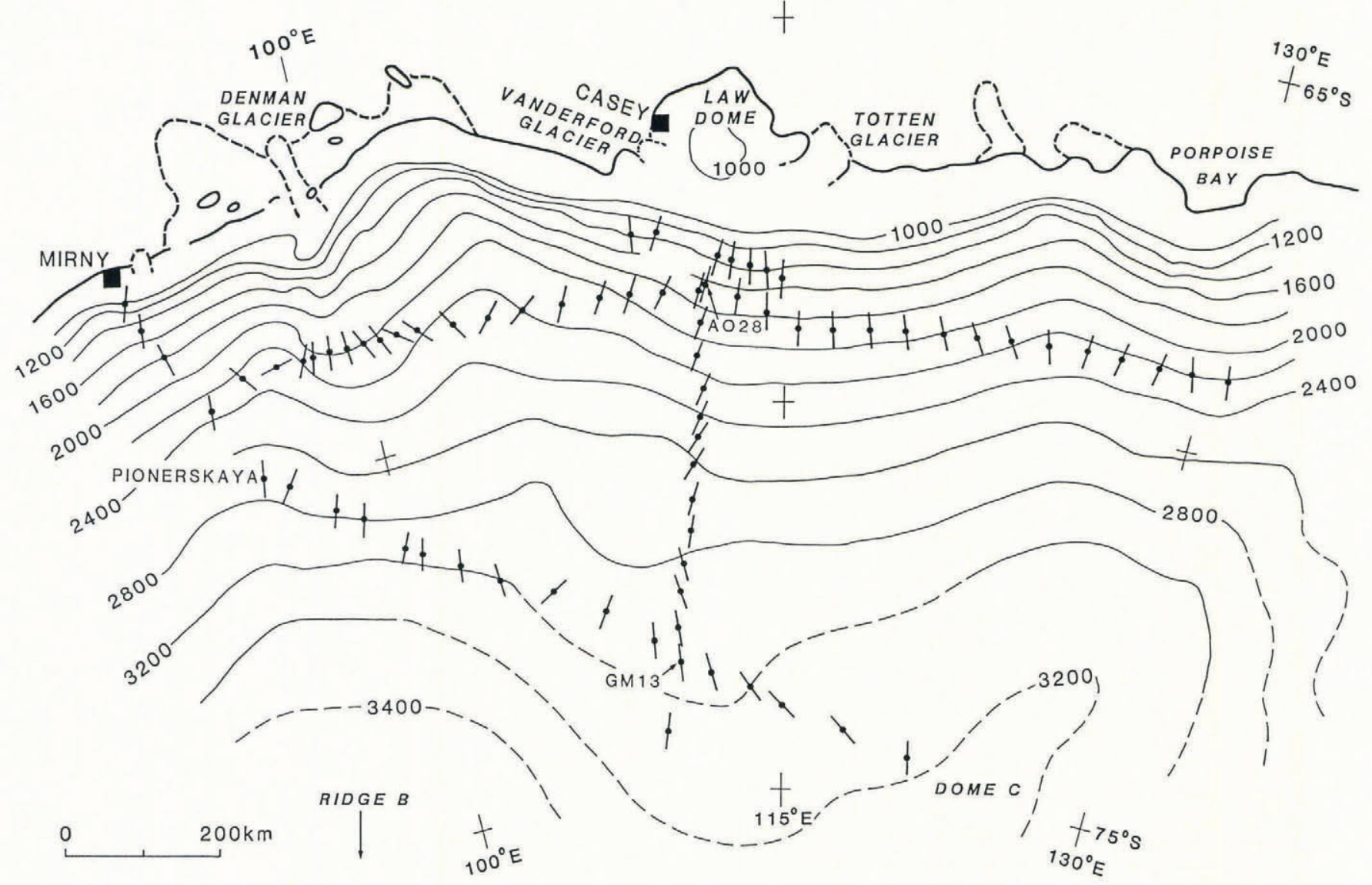

Fig. 1. Map of Wilkes Land, Antarctica, showing measured velocity directions at each survey station, and surface-elevation contours (at $200 \mathrm{~m}$ intervals from 1000 to $3400 \mathrm{~m}$ ) which have been smoothed to show the major topographic features. North of lat. $72.1^{\circ} \mathrm{S}$, the contours are taken from Zwally and others (1983) but further south the contours are based on those of Drewry (1983) which have been modified to tie with the SEASAT contours. 
$2000 \mathrm{~m}$ elevation contour was selected for this transect in order to measure the outflow from the greater part of the study region, but to be far enough inland to avoid most of the disturbance from large ice streams and outlet glaciers. The third transect, which for much of its length between Pionerskaya and Dome C approximates the $3000 \mathrm{~m}$ elevation contour, provides flow data across the interior of Wilkes Land. A short fourth section, inland of Mirny, connects the westernmost points of the $2000 \mathrm{~m}$ transect and the Pionerskaya-Dome $\mathrm{C}$ transect.

\section{MEASUREMENTS}

Ice velocities, along the transects, were determined from the displacement of surface markers over time intervals ranging from 1 to 6 years (Hamley, 1985; Jones and Hendy, 1985; Medhurst, 1985). During each oversnow traverse survey, the geodetic position of an ice-movement marker was determined by satellite-doppler survey techniques (Young, 1979a). The accuracy of the velocity measurement is dependent on the total displacement of the marker, the accuracy of each position measurement, and the time interval between surveys. The position accuracy is generally of the order of $1-2 \mathrm{~m}$ in each coordinate. The achieved accuracy for the velocity measurement is better than $10 \%$ and typically $1-3 \%$ in magnitude, and $5^{\circ}$ and typically $1-2^{\circ}$ in azimuth.

Surface elevations along the transects were determined barometrically with absolute height control provided at the satellite survey stations. Ice thickness was measured continuously along the transects with a $100 \mathrm{MHz}$ radio echosounder. Figures 2 and 3 show the profiles of surface and bedrock elevations along the $2000 \mathrm{~m}$ transect (Jones and Hendy, 1985; Medhurst, 1985) and flow-line transect, respectively. Regional surveys over Wilkes Land of surface elevation and ice thickness have been made by airborne radio echo-sounding (RES) along flight lines which were spaced at about $100 \mathrm{~km}$ intervals (Drewry, 1983). But the data are limited to the area east of the flow-line transect, in eastern Wilkes Land, and south of about lat. $73.5^{\circ} \mathrm{S}$ in western Wilkes Land. Drewry (1983) used the airborne RES data, supplemented by ground measurements along the Pionerskaya-Dome $\mathrm{C}$ transect and along the Mirny-Vostok traverse line, to compile a set of contour maps of surface elevation, ice thickness, and bedrock elevation.

Another source of surface elevations is the radaraltimeter data from SEASAT presented by Zwally and others (1983). They presented a contour map of the ice-sheet surface from the coast to lat. $72.1^{\circ} \mathrm{S}$, the southern limit of the satellite coverage. These data provide greater detail than the exisiting RES surveys, but the coverage is not uniform (even though the satellite tracks were evenly spaced) because of a limitation in the design of the satellite-borne altimeter. The best coverage and greatest detail are found in the interior near the southern limit of the satellite data where the ice-sheet surface is smooth. Closer to the coast, where surface slopes are larger, and the rate of change greater, the coverage is poor, particularly over pronounced features such as the large outlet glaciers. The maps of Zwally and others (1983) and Drewry (1983) are used to compile the surface-elevation map shown in Figure 1.

\section{FLOW REGIME}

The ice discharge from Wilkes Land occurs through two major glacier systems and across the coast with few distinct ice streams. Along about half of the coastline the ice sheet flows into floating ice shelves. Most of the mass loss results from icebergs calving into the ocean from the edge of the ice shelves, the glacier tongues, or directly from the coastal ice cliffs. The remainder of the mass loss occurs predominantly as melting from the submerged surfaces.

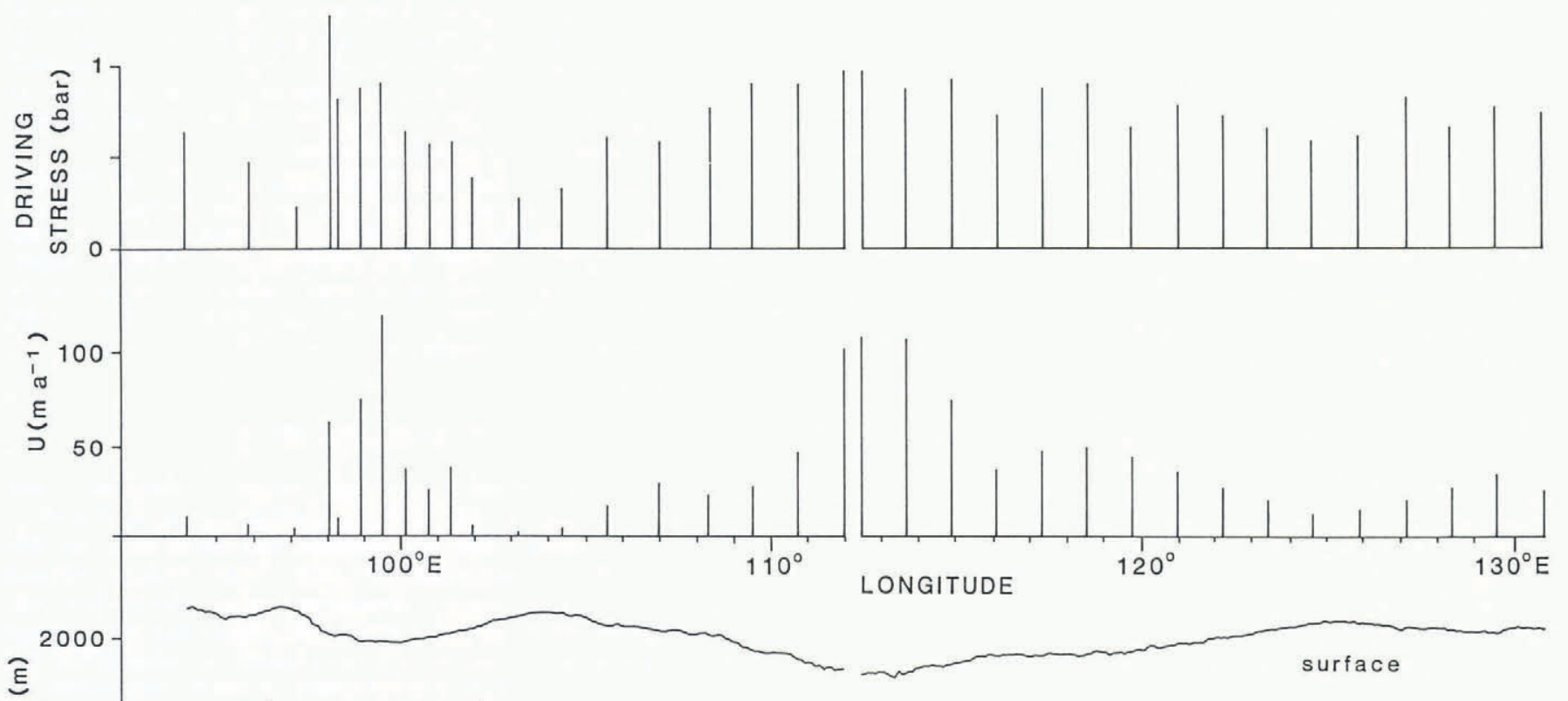

는

100

.

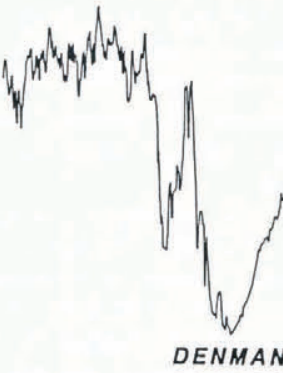

GLACIER

GLACIER

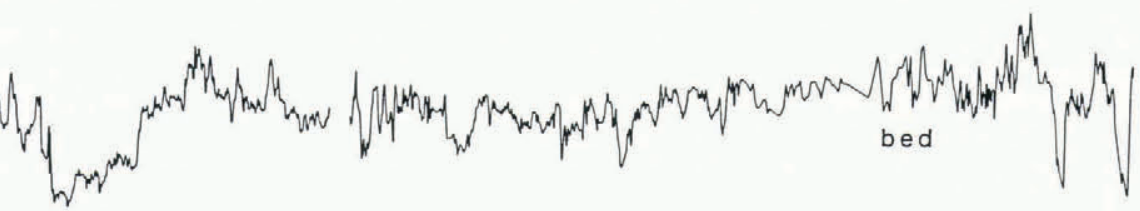

Fig. 2. Profile along the $2000 \mathrm{~m}$ transect showing measured surface and bedrock elevations (ma.s.l.) together with the magnitude of the measured velocities and driving stress (bar octahedral) at each survey station. The labels, Denman Glacier, Totten Glacier, and Porpoise Bay, indicate the zones which flow into the major outlet streams and embayments. 


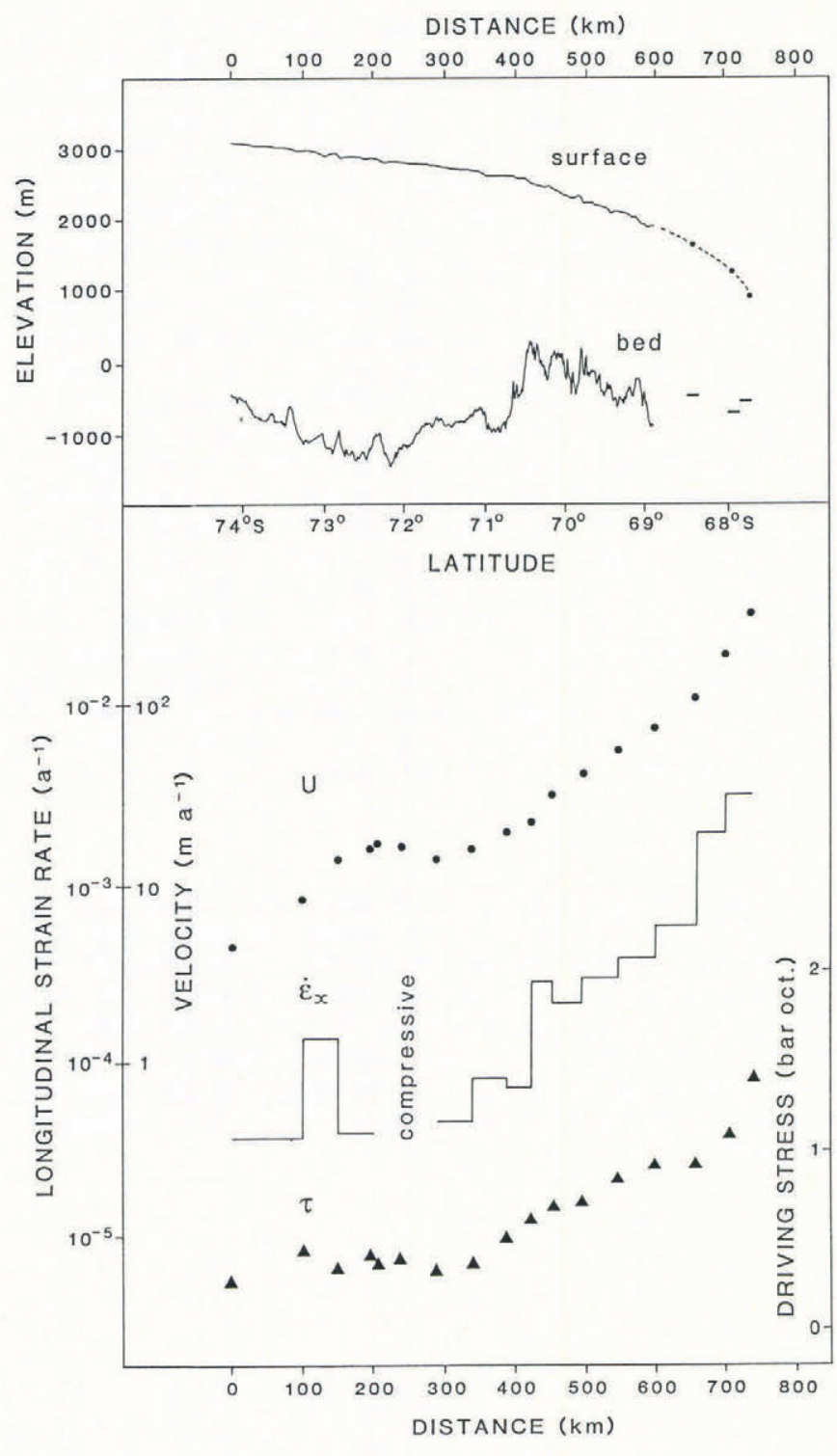

Fig. 3. Longitudinal profile along the flow-line transect inland of Casey showing measured surface and bedrock elevations, measured surface velocities, derived longitudinal (extensive) strain-rates between survey stations, and driving stress (bar octahedral).

Young (1979b) divided the ice sheet in Wilkes Land into a number of drainage basins on the basis of their outlets. Totten and Vanderford Glaciers, on the southern boundary of Law Dome, and Denman Glacier and neighbouring ice streams near long. $100^{\circ} \mathrm{E}$ account for the major part of the outflow from the interior of the ice sheet.

Inland of Denman Glacier there is a large and prominent valley, about $300 \mathrm{~km}$ across, in the surface of the ice sheet which leads into the Denman Glacier system. The measured velocity directions along the $2000 \mathrm{~m}$ transect, between long. $97^{\circ}$ and $102^{\circ} \mathrm{E}$ (Fig. 1), show strong convergence of the flow into this valley up-stream of the head of the main Denman Glacier stream (Young, 1989). The side boundaries of the catchment area of the Denman Glacier system are defined by the topographic ridges to each side of this valley. There is strong divergence of the flow on the crests of these ridges (Fig. 1). Flow west of this valley is directed towards Helen Glacier near Mirny; and flow east of the valley is towards the coast west of Vanderford Glacier. The surface ridges are approximately located over bedrock highs with elevations up to $1000 \mathrm{~m}$ a.s.l. (Fig. 2).

The western boundary of the catchment can be traced up-stream through Pionerskaya to Ridge B $\left(78^{\circ} \mathrm{S}, 95^{\circ} \mathrm{E}\right)$ (Young, 1979b; Drewry, 1983). There is divergence of the flow near Pionerskaya and the bedrock is also relatively high in this region (see Young, 1979b, fig. 5a). The eastern boundary of the catchment area is less well defined. Strong divergence of the flow near a point $\left(72^{\circ} \mathrm{S}, 104^{\circ} \mathrm{E}\right)$ on the Pionerskaya-Dome $\mathrm{C}$ transect indicates the location of the boundary in this area. There is no obvious bedrock high on the profile of bedrock elevations (see Young 1979b, fig. 5a). We postulate that there is a large bedrock high north of this area around $71^{\circ} \mathrm{S}, 105^{\circ} \mathrm{E}$ that is controlling the flow and shape of the ice sheet, dividing the flow between the catchments of the Denman Glacier and Totten Glacier system. This bedrock feature may or may not be contiguous with the bedrock high further north identified on the elevation profile of the $2000 \mathrm{~m}$ transect at about long. $103^{\circ} \mathrm{E}$ (Fig. 2). Apart from along the traverse routes, there are no RES data over western Wilkes Land which can be used to test the above postulate.

Totten Glacier drains a large area in the interior of Wilkes Land with the southern boundary along the ridge line between Ridge B and Dome C (Young, 1979b; Drewry, 1983). Vanderford Glacier drains a narrow band bordering the western edge of the Totten Glacier catchment and adjoining the Denman Glacier catchment near $72^{\circ} \mathrm{S}, 105^{\circ} \mathrm{E}$ The southern extent of the Vanderford Glacier catchment is not well defined by the available information.

Immediately inland of Totten Glacier, between lat. $68^{\circ}$ and $69^{\circ} \mathrm{S}$, the flow is almost parallel with slight convergence. The division of the flow, south of Law Dome between Totten Glacier and Vanderford Glacier to the west, is defined by velocity measurements given by Budd and Young (1979). In the interior near lat. $73^{\circ} \mathrm{S}$ in the vicinity of GM13, the measured velocity directions along the Pionerskaya-Dome $\mathrm{C}$ transect show a broad area of convergence of the flow from between Ridge $B$ and Dome C. Flow from the vicinity of Dome $C$ to the north-west follows the form of Aurora Subglacial Basin (Drewry, 1983). North of GM13, there is a marked change in velocity direction as the ice tends to follow the form of the deeper part of the basin (bedrock elevations of -1000 to $-1500 \mathrm{~m}$ ) round a broad bedrock high located to the east. This bedrock feature, centred on $73^{\circ} \mathrm{S}, 117^{\circ} \mathrm{E}$, with elevations reaching above sea-level, appears to control the shape of the ice sheet and the flow to the north and north-west of Dome C. At about lat. $71^{\circ} \mathrm{S}$ along the flow-line transect there is a sharp rise of over $1000 \mathrm{~m}$ in the bedrock to elevations above sea-level (Fig. 3), corresponding to the northern limit of the subglacial basin.

Measured velocity directions along the $2000 \mathrm{~m}$ transect show that the flow to the east of the Totten Glacier catchment is almost planar (Fig. 1). There is a gradual change in direction with divergence across a broad surface topographic ridge which runs from Dome $\mathrm{C}$ to the coast near long. $122^{\circ} \mathrm{E}$. The flow to the east of this ridge discharges through Porpoise Bay.

\section{SURFACE-VELOCITY DISTRIBUTION}

Figure 1 shows that the velocity directions are generally normal to the average surface-elevation contours. It is worth noting that the contours are based only on the surface-elevation measurements and were drawn without reference to the velocity directions. It is likely that any misalignment between the velocity direction and the surface slope indicates a local feature or effect not represented by the averaged contours. Misalignment is most noticeable on the Pionerskaya-Dome $\mathrm{C}$ transect near long. $104^{\circ} \mathrm{E}$, where elevation data are limited and velocities are small, and to the west of the Denman Glacier valley near the $2200 \mathrm{~m}$ contour, where large changes in velocity direction occur over a short distance and where elevation data are not available in sufficient detail.

The magnitudes of the velocity along the $2000 \mathrm{~m}$ transect and along the flow-line transect are shown in Figure 2 and 3 , respectively. There is a smooth and steady gradation in velocity along the transects, both parallel to and across the direction of flow. Figure 3 also shows the average longitudinal (extensive) strain-rate between each pair of adjacent measured velocity points. In the interior, the longitudinal strain-rate is generally less than $10^{-4} \mathrm{a}^{-1}$, and over an $80 \mathrm{~km}$ section the strain is compressive. At about $71^{\circ} \mathrm{S}$ there is a sharp increase in strain-rate, in association with a general reduction in ice thickness, followed by a 
steady increase in strain-rate towards the coast.

Along the $2000 \mathrm{~m}$ transect, between long. $110^{\circ}$ and $130^{\circ} \mathrm{E}$, the ice thickness is roughly constant, in the range 2000-2500 m (Fig. 2). Towards the eastern end, there are two narrow valleys in the bedrock about $10-20 \mathrm{~km}$ wide where the ice thickness exceeds $3400 \mathrm{~m}$. In the west there are very large changes in ice thickness between a minimum of about $1000 \mathrm{~m}$ and a maximum of $3900 \mathrm{~m}$ inland of Denman Glacier. Measured ice velocities along the $2000 \mathrm{~m}$ transect are typically less than $50 \mathrm{~m} \mathrm{a}^{-1}$ except inland of the major outlets, Totten and Denman Glaciers, where velocities exceed $100 \mathrm{~m} \mathrm{a}^{-1}$ between 200 and $250 \mathrm{~km}$ up-stream of the grounding zone. The flow into Totten Glacier appears as a broad band of higher velocity about $200 \mathrm{~km}$ wide and not associated with any noticeable bedrock depression. By contrast, the flow into Denman Glacier is narrower and confined to two very deep subglacial depressions.

Thus, the measurements show that, for the thick grounded ice sheet in the interior of East Antarctica, the ice velocity varies smoothly in both direction and magnitude at a scale of $50-100 \mathrm{~km}$. One exception to this pattern can be found inland of Denman Glacier on the western side of the zone draining through that outlet. Most of the flow passes through the broad deep valley, centred on long. $100^{\circ} \mathrm{E}$, which reaches $2000 \mathrm{~m}$ below sea-level (Fig. 2). An additional part of the flow passes down an adjacent valley, at about long. $98^{\circ} \mathrm{E}, 25 \mathrm{~km}$ wide and separated from the main valley by a narrow bedrock high reaching $500 \mathrm{~m}$ a.s.1. The ice velocity in the centre of the valley is $67 \mathrm{~m} \mathrm{a}^{-1}$ but at a second point, $10 \mathrm{~km}$ to the east located on the western flank of the bedrock high, the velocity is only $9 \mathrm{~m} \mathrm{a}^{-1}$.

\section{DRIVING STRESS}

For large grounded ice sheets, the gravity-induced down-slope shear stress determines the broad-scale pattern of ice motion. We follow Cooper and others (1982) in using the terminology "driving stress", rather than basal shear stress, to describe the term

$$
\tau=(2 / 3)^{\frac{1}{2}} \rho g Z \alpha
$$

where $\rho$ is the ice density, $g$ is the acceleration due to gravity, $Z$ is the thickness, $\alpha$ is the surface slope, and the constant $(2 / 3)^{\frac{1}{2}}$ has been introduced to their formulation to convert stress to the equivalent octahedral value (Jacka and Budd, 1989). In order to obtain values of the driving stress which are meaningful in a discussion of the velocity distribution, it is necessary to average the values of the surface slope and ice thickness over some horizontal distance scale. (See, for example, the discussion in Paterson (1981).) The determination of an average slope over an appropriate distance along the flow is the most important factor, as slope can locally assume positive or negative values across surface undulations, even many hundreds of kilometres from the coast (Fig. 3). Young and others (1982) found, from data collected along the flow-line transect, that an averaging scale of 20-30 times the ice thickness was required, i.e. of the order of $100 \mathrm{~km}$ for ice $4000 \mathrm{~m}$ thick. Averaging over this distance smooths out the effects of longitudinal stress gradients and other stresses which control the flow of the ice sheet over an irregular bedrock topography. Cooper and others (1982) used a sample area $(111 \mathrm{~km} \times 111 \mathrm{~km})$ to calculate a mean slope, derived from a best-fit plane to the surface-elevation data, and average ice thickness from all data within the box. They applied an averaging to the resultant values but found some residual undulating pattern in the distribution of driving stress in eastern Wilkes Land. Based on experience gained from analysis of the traverse data, it is likely that this residual undulating pattern is a result of the spacing of 50 or $100 \mathrm{~km}$ between their flight lines.

For the present study, the driving stress is derived for each velocity point using the measurements of ice thickness along the transects and the maps of surface elevation of Drewry (1983) and Zwally and others (1983). The surface slope is determined over a distance of at least 20 and typically 25-30 times the ice thickness, approximately centred on the velocity point. The value of ice thickness used in Equation (1) is the average over a distance of
20-40 km, depending on ice thickness and irrespective of whether the transect is along or across the flow direction.

The values of driving stress along the $2000 \mathrm{~m}$ transect are shown in Figure 2. For points with similar ice thickness, temperature-depth distribution, and ice rheology, the velocity-depth profile and hence the surface velocity should vary as some power of the shear stress (Paterson, 1981). For the eastern part of the $2000 \mathrm{~m}$ transect (Fig. 2), the pattern of driving stress approximately follows the pattern of velocity but with a smaller range in relative magnitude, which is consistent with the above relationship. In the west, the zone with large values of driving stress associated with the high velocities leading into Denman Glacier is the main feature. Very high stresses are associated with only moderate velocities in the narrow valley, on the west of the main Denman Glacier flow at about long. $98.3^{\circ} \mathrm{E}$.

\section{MEAN SHEAR STRAIN-RATE VERSUS DRIVING} STRESS

Using the measured surface velocity and the same value of ice thickness as in the calculation of driving stress (Equation (1)), the mean horizontal shear strain-rate can be calculated from

$$
\dot{\varepsilon}=(2 / 3)^{\frac{1}{2}} \frac{1}{2}(U / Z)
$$

where $U$ is the measured surface velocity, $Z$ is the ice thickness, and the constant $(2 / 3)^{\frac{1}{2}}$ converts the strain-rate to the equivalent octahedral value (Jacka and Budd, 1989). The relationship between mean shear strain-rate and driving stress, which is shown in Figure 4, is similar to that found by other workers (e.g. Budd and Smith, 1981; Cooper and others, 1982; Hamley and others, 1985). These data can be approximated by a relation of the form

$$
\dot{\varepsilon}=k \tau^{n}
$$

where $k$ is a constant and $n$ has a value between 3 and 3.2 depending on the weighting given to the individual points. For unit weighting in a linear regression of $\log \dot{\varepsilon}$ against $\log \tau$, the value of $n$ is 3.16 , and $r$ is equal to 0.86 . By contrast, Budd and Smith (1981) reported a value of 3.5 for a selection of cold ice masses, and Cooper and others (1982) gave a value of 2.51 for (eastern) Wilkes Land using balance velocities calculated from an unpublished accumulation distribution and the RES data of Drewry (1983). The velocity points reported by Hamley and others (1985) are a sub-set of the data reported here. Some of their velocity values have been revised to new values obtained with the completion of the re-surveys during 1984-86. They reported a value for $n$ of 3.21 but used a digitized version of the maps of Drewry (1983) as a basis for their calculation of driving stress over a $20 \mathrm{~km}$ grid interval.

Figure 4 also shows the relation between octahedral shear strain-rate and octahedral shear stress for different temperatures derived from laboratory measurements of minimum strain-rate for isotropic ice (Jacka and Budd, 1989), so that some similarities can be observed. For instance, the value of $n$ for the field data is close to 3 which is the value proposed for the laboratory data (Jacka and Budd, 1989). Most of the data points fall within a narrow temperature range $\left(-4^{\circ}\right.$ to $\left.-15^{\circ} \mathrm{C}\right)$, as related to the laboratory tests. But the plotted values are the shear strainrate averaged through the total ice thickness, whereas it is believed that most of the shear deformation actually occurs in the lowest one-third or one-quarter of the thickness, and hence in order to compare the two data sets it is necessary to increase the mean shear strain-rate by a factor of 3 or so. On the other hand, the laboratory data refer to minimum strain-rates for isotropic ice, whereas most deformation in the ice sheet is likely to occur in ice with a well-developed anisotropy for which the strain-rate will be greater by a factor of 3 or more (Jacka and Budd, 1989). But a rigorous derivation of surface velocities to compare with the field measurements that takes into account the effects of the stress and temperature distributions inside the ice mass, as well as the ice rheology, requires the 


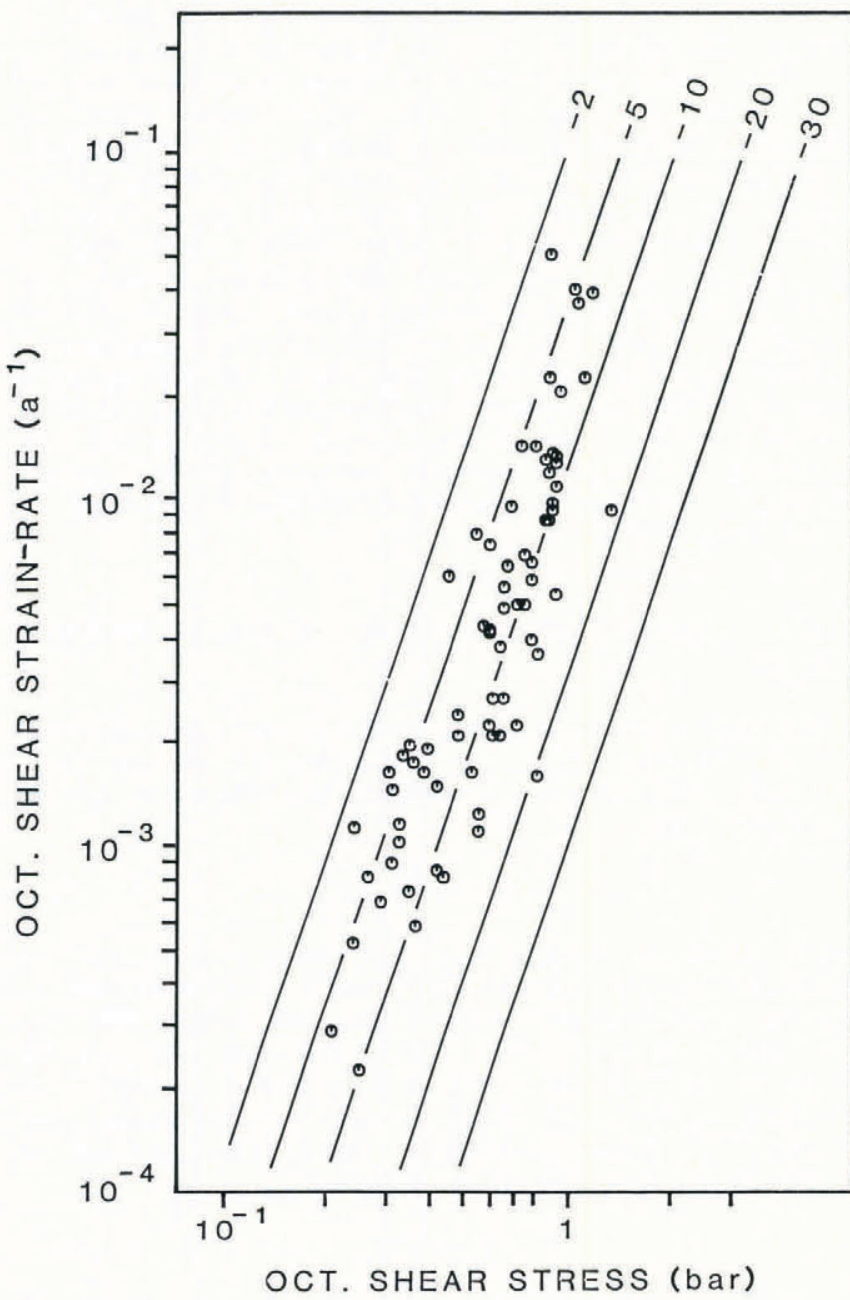

Fig. 4. Octahedral shear strain-rate versus octahedral shear stress. Each circle gives the value of mean shear strain-rate and driving stress at one of the measured velocity points. The mean shear strain-rate is calculated from $U / Z$, where $U$ is the measured surface velocity and $Z$ is the average ice thickness for the locality about the survey station. The driving stress is calculated from a value of the surface slope averaged over a distance (centred on the survey point) of 20-30 times the ice thickness and the same value of ice thickness, $Z$. The solid lines represent the relation between strain-rate and stress for different temperatures derived from laboratory measurements of minimum strain-rate for isotropic ice (Jacka and Budd, 1989). points can also be explained. Surface features on Landsat imagery (Young, 1989) show the longitudinal continuity, north and south of the $2000 \mathrm{~m}$ transect, of the two valleys inland of Denman Glacier. But a few kilometres north of the lower-velocity point, other features indicate that the ice thickness is significantly thinner, perhaps in the range $500-1000 \mathrm{~m}$. In addition, the snow-accumulation rate on the western side of the Denman Glacier area is high, in the range $400-600 \mathrm{~kg} \mathrm{~m}^{-2} \mathrm{a}^{-1}$. This, together with the relatively thinner ice thickness, leads to much colder basal temperatures and a very cold average column temperature. Elsewhere, particularly in the thicker ice, the basal temperatures are at, or close to, the pressure-melting point (Budd and Young, 1979; Budd and Jenssen, 1989). Because the horizontal shear deformation is occurring in very cold ice, and with the added restraint of a large ice-thickness reduction along the direction of flow, the velocity at this point can be expected to be small.

Part of the scatter in Figure 4 is related to the averaging scale used in the selection of the ice-thickness value for the calculation of the driving stress and strain-rate. The eastern half of the $2000 \mathrm{~m}$ transect, where the ice thickness is approximately constant, can again be used as a base line. A few individual points have higher values of driving stress, compared to adjacent points, than might be expected from the pattern of velocity variation. These points occur where the ice thickness is locally greater. A reduction in the value of ice thickness used in the calculations leads to a lower driving stress and higher mean shear strain-rate. This change in calculated values has the effect of producing a closer fit to the relation given by Equation (3) for data from the eastern half of the $2000 \mathrm{~m}$ transect. Thus, in considering the average flow properties, the effect of the ice flow is to smooth local variations up to $25 \%$ of the ice thickness over distances of $20-30 \mathrm{~km}$ across the direction of flow.

\section{CONCLUSION}

Measurements of surface velocity over the thick ice sheet in the interior of Wilkes Land, Antarctica, show that the flow of the ice varies smoothly in both direction and magnitude over a distance scale of at least 20 times the ice thickness. The surface velocity is aligned with the broadscale average surface slope. A comparison of the mean horizontal shear strain-rate with the driving stress at each of the measured velocity points shows that the bulk flow parameters of the ice sheet satisfy a power-law relation with an exponent between 3 and 3.2 , depending on the weighting given to the individual points. Part of the scatter about the relation can be attributed to insufficient averaging of the value of ice thickness used in the calculation of the bulk terms. A more rigorous assessment of the effect of the averaging scale and other influences, such as the temperature-depth profile and ice rheology, will be presented in a later paper.

\section{ACKNOWLEDGEMENTS}

1989; Dahl-Jensen, 1989).

Some of the scatter of individual data points in Figure 4 about a relation given by Equation (3) can be explained with a closer examination of the individual measurements. For instance, the two data points closest to the $-20^{\circ} \mathrm{C}$ line correspond to the two velocity points in the narrow valley on the western side of the Denman Glacier flow. For these points, the driving stresses are much higher than for other points with similar velocity or strain-rate. Between the two points there is a significant lateral shear strain-rate (average value of $2.4 \times 10^{-3} \mathrm{a}^{-1}$ compared to a value of $9.1 \times$ $10^{-3} \mathrm{a}^{-1}$ for the horizontal shear strain-rate at the higher velocity point). Deformation at this rate in the cold upper $60 \%$ of the ice thickness, which has an average temperature about $-30^{\circ} \mathrm{C}$, will lead to a significant restraint on the flow at the centre of the valley, counter-balancing the large driving stress. Some convergence of the flow into the valley will add a further restraining influence.

The very low velocity at the easternmost of these two
Many people have been involved in the collection of surveys was carried out by a field party, usually of six people, that worked away from Casey Station for a total of about 6 months each year. Countless other ANARE expeditioners assisted with preparations, communications, etc. Without their participation, support, and encouragement, none of this work would have been achieved. On five occasions, an Australian participated in the Soviet Antarctic Expedition traverses to Dome $\mathrm{C}$ at the invitation of the Arctic and Antarctic Research Institute, Leningrad. Processing of all the satellite-positioning data was undertaken in collaboration with the (then) Australian Division of National Mapping with satellite-ephemeris data supplied by the U.S. Defense Mapping Agency. The invaluable contribution of all organizations and personnel is gratefully acknowledged. the data presented here. Each of the Australian traverse 


\section{REFERENCES}

Anonymous. 1971. International Antarctic Glaciological Project. Polar Rec., 15(98), 829-833.

Bentley, C.R., W.F. Budd, V.M. Kotlyakov, C. Lorius, and G. de Q. Robin. 1972. The International Antarctic Glaciological Project standardization document. Polar Rec., 16(101), 349-364.

Budd, W.F. and D. Jenssen. 1989. The dynamics of the Antarctic ice sheet. Ann. Glaciol., 12, 16-22.

Budd, W.F. and I.N. Smith. 1981. The growth and retreat of ice sheets in response to orbital radiation changes. International Association of Hydrological Sciences Publication 131 (Symposium at Canberra 1979 - Sea Level, Ice and Climatic Change), 369-409.

Budd, W.F. and N.W. Young. 1979. Results from the I.A.G.P. flow-line study inland of Casey, Wilkes Land, Antarctica. J. Glaciol., 24(90), 89-101.

Cooper, A.P.R., N.F. McIntyre, and G. de Q. Robin. 1982. Driving stresses in the Antarctic ice sheet. Ann. Glaciol., 3, 59-64.

Dahl-Jensen, D. 1989. Two-dimensional thermo-mechanical modelling of flow and depth-age profiles near the ice divide in central Greenland. Ann. Glaciol., 12, 31-36

Drewry, D.J., ed. 1983. Antarctica: glaciological and geophysical folio. Cambridge, University of Cambridge. Scott Polar Research Institute.

Hamley, T.C. 1985. Glaciological measurements on the $1983 / 84$ Soviet traverse from Mirny to Dome C. ANARE Res. Notes, 28, 180-184.

Hamley, T.C., I.N. Smith, and N.W. Young. 1985.
Mass-balance and ice-flow-law parameters for East Antarctica. J. Glaciol., 31(109), 334-339.

Jacka, T.H. and W.F. Budd. 1989. Isotropic and anisotropic flow relations for ice dynamics. Ann. Glaciol., 12, 81-84.

Jones, D. and M. Hendy. 1985. Glaciological measurements in eastern Wilkes Land, Antarctica. ANARE Res. Notes, $28,164-173$.

Medhurst, T.G. 1985. Glaciological measurements in western Wilkes Land, Antarctica. ANARE Res. Notes, 28, 174-179.

Paterson, W.S.B. 1981. The physics of glaciers. Second edition. Oxford, etc., Pergamon Press.

Young, N.W. 1979a. Application of Doppler satellite observations to the study of ice-flow in East Antarctica problems peculiar to Doppler surveys in high latitudes. In Proceedings of the Second International Geodetic Symposium on Satellite Doppler Positioning, Austin, Texas, 1979. Vol. 1. Austin, TX, University of Texas. Applied Research Laboratories, 373-391.

Young, N.W. 1979b. Measured velocities of interior East Antarctica and the state of mass balance within the I.A.G.P. area. J. Glaciol., 24(90), 77-87.

Young, N. 1989. Surface velocities of Denman Glacier, Antarctica, derived from Landsat imagery. (Abstract.) Ann. Glaciol., 12, 218.

Young, N.W., D. Sheehy, and T. Hamley. 1982. Ice flow along an IAGP flow line, Wilkes Land, Antarctica. (Abstract.) Ann. Glaciol., 3, 346.

Zwally, H.J., R.A. Bindschadler, A.C. Brenner, T.V. Martin, and R.H. Thomas. 1983. Surface elevation contours of Greenland and Antarctic ice sheets. J. Geophys. Res., 88(C3), 1589-1596. 